Revista Destaques Acadêmicos, Lajeado, v. 10, n. 1, 2018. ISSN 2176-3070

DOI: http://dx.doi.org/10.22410/issn.2176-3070.v10i1a2018.1779

http://www.univates.br/revistas

\title{
PREÇOS DE TRANSFERÊNCIA - OPORTUNIDADES E RESTRIÇÕES FISCAIS NAS TRANSAÇÕES ENTRE EMPRESAS VINCULADAS
}

\author{
Marcelo Luis Scheeren ${ }^{1}$, Adriano José Azeredo²
}

\begin{abstract}
Resumo: o estudo identifica as oportunidades e restrições fiscais impostas pela legislação do preço de transferência tanto nas importações quanto nas exportações entre empresas vinculadas. A legislação brasileira regulamentada pela Lei $\mathrm{n}^{\circ}$ 9.430/96, apresenta restrições quando as operações ocorrem entre empresas de um mesmo grupo econômico enquadrando-as em métodos relacionados ao preço de transferência. A legislação internacional baseia-se em preços comparáveis praticados. A pesquisa de caráter exploratório, se aproxima de um estudo de caso pois utiliza uma empresa exportadora do Vale do Taquari, RS, onde constata-se que pela legislação fiscal brasileira a empresa se enquadra em apenas um dos métodos existentes para as operações realizadas denominado de CAP (Custo de Aquisição ou de Produção mais Tributos e Lucro). Em relação aos comparáveis, os preços praticados pela empresa são até $25 \%$ menores do que os praticados pelo mercado internacional.
\end{abstract}

Palavras-chave: Preços de transferência. Legislação, arm's length. Importação. Exportação.

\section{INTRODUÇÃO}

Nos últimos vinte anos, a preocupação com os preços de transferência vem aumentando entre as empresas. No Brasil, o assunto surgiu com a Lei $\mathrm{n}^{\circ}$ 9.430, de 27 de dezembro de 1996, quando a legislação federal regulamentou pela primeira vez a questão dos preços de transferências em operações internacionais de bens, serviços, direitos juros e outras operações. O objetivo desta legislação tributária nacional foi o de diminuir o superfaturamento nas importações e o subfaturamento nas exportações, nas operações com pessoas vinculadas, tentando dessa forma, coibir a evasão fiscal.

1 Graduado em Ciências Contábeis e Gestão de Micro e Pequenas Empresas pela Universidade do Vale do Taquari - Univates.

2 Mestre em Ciências Contábeis pela Universidade do Vale do Rio dos Sinos, Brasil (2008). Professor Assistente da Universidade do Vale do Taquari - Univates, Brasil. 
No exterior esta legislação já é existente desde os anos de 1970, e a sua aplicação vem crescendo principalmente devido às operações envolvendo subsidiárias e as corporações multinacionais.

O termo "preço de transferência" tem sido utilizado para identificar os controles a que estão sujeitas as operações comerciais ou financeiras realizadas entre partes relacionadas, sediadas em diferentes jurisdições tributárias, ou quando uma das partes está sediada em paraíso fiscal. Em razão das circunstâncias peculiares existentes nas operações realizadas entre essas pessoas, o preço praticado nessas operações pode ser artificialmente estipulado e, consequentemente, divergir do preço de mercado negociado por empresas independentes, em condições arm's length análogas - preço com base no princípio, (equiparação de preços).

É considerado preço de transferência, o valor cobrado por uma empresa na transferência de bens ou serviços a outra empresa que a ela seja relacionada. Desta maneira estes preços não são os que acontecem no mercado aberto e que não podem ser comparados em outras operações comparáveis.

Assim, este trabalho pretende demonstrar as restrições tributárias brasileiras existentes nas transações internacionais de bens, serviços ou direitos entre empresas vinculadas que constituem partes relacionadas em diferentes países.

O estudo toma como exemplo de aplicação da legislação dados do período de 2017 de uma empresa exportadora do Vale do Taquari, RS, vinculada a empresa sediada na Europa.

\section{REVISÃO TEÓRICA}

O preço de transferência é uma operação praticada tanto na importação quanto na exportação de bens, serviços e direitos, entre pessoas jurídicas consideradas vinculadas. Para sua análise se faz necessário à abordagem teórica quanto aos preços e transferência, evasão, fraude, elisão e sonegação.

As pessoas jurídicas consideradas vinculadas, necessitam de um controle maior, isso se faz necessário para que a mesma não incorra em nenhum tipo de sonegação ou elisão fiscal para com isso não realizar atos de forma que possam ser considerados ilícitos pelo fisco.

Por se tratarem de operações entre vinculadas as mesmas precisam ter um cuidado muito grande para não represar lucros, ou seja, vender o produto para a sua vinculada a um valor inferior ao estabelecido pela legislação, diante disso a mesma acaba reduzindo o seu lucro na venda e consequentemente acabam reduzindo os seus lucros e com isso a mesma acaba lesando os cofres no que se refere ao recolhimento do imposto sobre o lucro. 


\subsection{Elisão, elusão e evasão e sonegação fiscal}

A elisão fiscal são práticas realizadas em procedimentos lícitos realizados por empresas, com a finalidade de postergar a obrigação tributária e reduzir o ônus tributário empresarial, é desenvolvida através da adequação do contribuinte à melhor forma de tributação, executado em conformidade com os sistemas fiscais que possibilitem a redução de tributos (OLIVEIRA, 2013).

Andrade Filho (2009), Amaral (2003), Oliveira (2013) e Sá (2007), entendem que a elisão fiscal consiste em uma atividade lícita, onde as empresas encontram alternativas, estas sempre em observância com a legislação vigente, com o intuito na economia de tributos, diminuindo desta maneira os seus encargos tributários, sendo estes todos atos lícitos da atividade.

Conforme Tôrres (2003), a elusão fiscal ocorre quando a empresa se utiliza de negócios aparentemente válidos, porém construídos com fraudes, ou ainda negócios simulados a fim de gerar o efeito de afastamento da incidência de tributos.

Para os autores Oliveira (2013) e Carvalho Santos apud Andrade Filho (2009), a elusão fiscal é algo transparente ao fisco, pois atende a todos os requisitos exigidos, uma vez que os mesmos não são ocultos ou inexistentes, pois o contribuinte assume o risco através do resultado ou seja atos enganosos, sendo que o negócio simulado é divergente do que apresenta o realizado, sendo uma dissimulação que oculta o fato real.

A evasão fiscal, também conhecida como sonegação fiscal, ocorre quando as pessoas jurídicas se utilizam de meios ilícitos para evitar o pagamento de tributos, impostos e taxas omitindo informações e apresentando falsas declarações. Além disso, a evasão fiscal ocorre quando o contribuinte deixa de recolher os tributos devidos.

Sonegação fiscal é a ocultação dolosa, mediante fraude, astúcia ou habilidade, do recolhimento de tributo devido ao Poder Público. No artigo $1^{\circ}$ da Lei n. 8.137/90, qual seja, considerando delitos contra a ordem tributária a supressão ou redução de tributo ou contribuição social ou acessório, e depois enumerando, taxativamente, quais as modalidades de conduta que podem levar a tal supressão ou redução, constituindo genericamente o que seja sonegação fiscal.

Para os autores Oliveira (2013), Guerreiroapud Oliveira (2009), Amaral (2003), Andrade Filho (2009), Martins (2006) e Tôrres (2003), a sonegação fiscal ocorre através de omissões dolosas com o intuito de retardar ou impedir mesmo que parcial ou total a ocorrência do fato gerador, desta forma diminuindo a sua carga tributária, desta maneira iniciando a sonegação.

Conforme Oliveira (2013, p. 192), “a evasão fiscal pode ser conceituada como toda e qualquer ação ou omissão tendente a elidir, reduzir ou retardar o cumprimento da obrigação tributária", também pode ser entendida como 
a fuga do cumprimento da obrigação já existente por forma ilícita, que não corresponde às exigências da elisão, que são a omissão anterior ao fato gerador, ato que não se contraponha à disposição legal e a omissão efetiva e não simulada.

\subsection{Fraudes}

Fraude é uma ação que não condiz com a verdade dos fatos, um esquema ilícito ou de má fé criado para obter ganhos pessoais ou também um modo de enganar ou iludir o Fisco. Deste modo, as pessoas jurídicas falsificam documentos e omitem operações.

Para os autores Tôrres (2003), Sá (2007) e Oliveira (2009), a fraude pode ser entendida como uma ação culposa, repudiada pela ética e pela moral, sendo que a mesma merece reprovação, pois o contribuinte age de modo deliberadamente contra as regras legais, com o intuito de fugir do ônus tributário, mediante distorções abusivas das formas jurídicas, bem como pelo ato simulado, que não é instrumento de planejamento tributário.

\subsection{OCDE e o princípio de arm's length}

A Organização para a Cooperação e Desenvolvimento Econômico OCDE atua nos âmbitos internacional e intergovernamental e reúne os países mais industrializados do mundo e alguns países emergentes, como México, Chile, Coreia do Sul e Turquia. A mesma diz que o Transfer Price é o termo utilizado para referir-se ao problema da distribuição de lucros entre as partes de um mesmo grupo empresarial (BRASIL, 2017).

No âmbito da Organização, os representantes efetuam o intercâmbio de informações e alinham políticas, com o objetivo de potencializar seu crescimento econômico e colaborar com o desenvolvimento de todos os demais países membros.

O Brasil ainda não aderiu a OCDE, mas o relacionamento entre a entidade e o país aprofundou-se a partir de 1999, quando o Conselho da OCDE decidiu criar um programa direcionado ao Brasil.

Em maio de 2007, o Conselho Ministerial da OCDE decidiu "fortalecer a cooperação da OCDE com o Brasil, China, Índia, Indonésia e África do Sul" por meio do programa de enhancedengagement, (programa através da qual demais países conseguem a adesão a OCDE) tornando possível a adesão desses países à OCDE. Em 2012, esses cinco países passaram a ser considerados keypartners (parceiros-chave) na Organização.

O principio arm's length (regra básica de preço de transferência usada na área tributária internacional) surgiu em 1927, quando este foi incorporado ao modelo da Liga das Nações, a mesma foi utilizada posteriormente na legislação do México (1943) e Londres (1946). 


\subsection{Partes Relacionadas - Pessoas Vinculadas - Paraísos Fiscais}

O conceito de pessoa vinculada encontra-se no art. 23 da Lei $n^{\circ} 9.430 / 96$. $\mathrm{O}$ art. $2^{\circ}$ da IN n ${ }^{\circ}$ 243/02 explica, em detalhes, quando uma pessoa física ou jurídica domiciliada no exterior é considerada vinculada à uma pessoa jurídica domiciliada no Brasil.

Para Rossetto (1999, p. 73) é "considerada parte relacionada, quando uma empresa participa de forma direta ou indireta, na administração, controle ou capital de outra empresa ou ainda, quando mesmas pessoas possuem este tipo de relacionamento com ambas as empresas".

Consideram-se partes relacionadas aquelas em que uma possui o poder, o controle da outra, ou que possua influência significativa sobre a outra em seu processo decisório financeiro e operacional (INTERNATIONAL ACCOUNTING STANDARDS COMMITTE, 1998).

No Brasil, as operações realizadas entre pessoas físicas e jurídicas residentes em paraísos fiscais (Países que possuem uma tributação favorecida. Para a legislação brasileira são aqueles que não tributam ou tributam a sua renda com um percentual igual ou inferior a $20 \%$. Instrução Normativa SRF $n^{\circ}$ 243/202) também estão sujeitos á legislação do preço de transferência, mesmo que não haja vinculo entre as partes relacionadas.

\subsection{Preços de Transferência - Transfer Pricing}

Com o surgimento da Lei $\mathrm{n}^{\circ} 9.430$ de 27 de dezembro de 1996, a legislação federal regulamentou pela primeira vez os preços de transferência em operações internacionais de bens, serviços e direitos entre empresas vinculadas com a intenção de coibir o que chamamos de evasão fiscal.

O termo transfer pricing ou preço e transferência pode ser definido como sendo "o preço que uma subunidade (segmento, departamento, divisão, etc.) de uma organização pelo produto ou serviço fornecido a uma outra organização" e tem sido objeto de grandes discussões em níveis mundiais (HORNGREN, 2000, p. 639).

A mesma passou por diversas alterações e modificações até chegar na IN RFB n ${ }^{\circ} 1312 / 2012$, sendo que estes métodos entram em vigor a partir de janeiro de 2013. 
Quadro 1 - Métodos Instrução Normativa Receita Federal do Brasil nº 1312/2012

\begin{tabular}{|l|l|}
\hline \multicolumn{1}{|c|}{ Importação } & \multicolumn{1}{|c|}{ Exportação } \\
\hline PIC - Preços Independentes Comparados & PVEx - Preço de Venda nas Eportações \\
\hline PRL - 20\% - Preço de RevendaMenos Margem de Lucro & PVA - Preço de Venda no Atacado no País de Destino \\
\hline PRL - 30\% - Preço de RevendaMenos Margem de Lucro & PVV - Preço de Venda no Varejo no País de Destino \\
\hline CPL - 40\% - Custo de Produção mais Lucro & PVA - Preço de Venda no Atacado no País de Destino \\
\hline PCl - Preço sob Cotação na Importação & Pecex - Preço sob Cotação na Exportação \\
\hline
\end{tabular}

Fonte: Silva (2014, p. 26).

Em comparação dos métodos eleitos pelo Brasil com os previstos pela OCDE e na legislação norte-americana, verifica-se extrema semelhança entre eles.

Quadro 2 - Comparativo dos métodos eleitos pelo Brasil e previstos pela OCDE

\begin{tabular}{l|c|c|c}
\hline Importação & Brasil & OCDE & EUA \\
\hline & PIC & CUP & CUP \\
\hline & PRL & RPM & RPM \\
\hline & CPL & CPM & COM \\
\hline Exportação & PVEX & CUP & CUP \\
\hline & PVA/PVV & RPM & RPM \\
\hline & CAP & CPM & COM \\
\hline
\end{tabular}

Fonte: PriceWaterhouse (1998, p. 68).

\subsection{Preço parâmetro}

Preço parâmetro é o preço apurado por meio dos métodos dos Preços de Transferência constantes da legislação brasileira, a mesma serve como referência na comparação dos preços efetivamente praticados pela empresa.

Conforme Silva (2014), na exportação: quando o preço parâmetro apurado nos métodos de exportação, for maior que o praticado, isso significa que o contribuinte reconheceu uma receita menor, desta forma a diferença que exceder ao valor já apropriado na escrituração deverá ser adicionada ao lucro líquido, desta forma a empresa terá uma nova base de cálculo da Contribuição Social Lucro Líquido (CSLL) e do Imposto de Renda Pessoa Jurídica (IRPJ).

Conforme Silva (2014), na importação: quando o preço parâmetro apurado nos métodos de importação, for menor ao preço praticado isso significa que o contribuinte reconheceu como custo ou despesa um valor maior que o devido, desta forma a empresa deverá adicionar esta diferença da mesma 
forma a Contribuição Social Lucro Líquido (CSLL) e do Imposto de Renda Pessoa Jurídica (IRPJ).

\subsection{Métodos na importação e exportação}

Com a instituição da IN RFB 1312, de 28 de dezembro de 2012, foram instituídos os preços a serem praticados nas operações de compra e venda de bens, serviços ou direitos efetuados, por pessoas físicas ou jurídicas residentes e domiciliadas no Brasil, sendo elas pessoas físicas ou jurídicas residentes ou domiciliadas no exterior, sendo as mesmas consideradas vinculadas.

Diante dessa Instrução Normativa temos alguns critérios ou métodos que precisam ser observados quando efetuadas operações entre empresas consideras vinculadas, na importação e exportação.

\subsubsection{Do Método dos Preços Independentes Comparados (PIC)}

Será utilizada a média aritmética ponderada dos preços de bens, serviços ou direitos, idênticos ou similares, apurados no mercado brasileiro ou de outros países, em operações de compra e venda empreendidas pela própria interessada ou por terceiros em condições de pagamentos semelhantes, PriceWaterhouse (1998), Matos (1999), Silva (2014), Higuchi (2014) e art. $8^{\circ}$ IN RFB 1312, de 28 de dezembro de 2012.

\subsubsection{Do Método do Preço de Revenda Menos Lucro (PRL)}

Este método é definido como a média aritmética ponderada dos preços de venda no País, dos bens, direitos e serviços importados, em condições de pagamentos semelhantes e calculados conforme a metodologia a seguir apresentada, Higuchi (2014) e art. $12^{\circ}$ IN RFB 1312, de 28 de dezembro de 2012.

I - 40\% para os setores de: Produtos farmoquímicos e farmacêuticos; Produtos de fumo; Equipamentos e instrumentos ópticos, fotográficos e cinematográficos; Máquinas, aparelhos equipamentos para uso odontomédico-hospitalar; Extração de petróleo e gás natural; e Produtos derivados de petróleo.

II - 30\% para os setores de: Produtos químicos; Vidros e produtos de vidro; celulose, papel e produtos de papel; e metalúrgica.

III $-20 \%$ para os demais setores.

\subsubsection{Do Método do Custo de Produção mais Lucro (CPL)}

Define como o custo médio ponderado de produção de bens, serviços ou direitos, idênticos ou similares, acrescido dos impostos e taxas cobrados na exportação no país onde tiverem sido originalmente produzidos, e de margem de lucro de $20 \%$ calculado sobre o custo apurado, PriceWaterhouse (1998), 
Matos (1999) e Silva (2014), Higuchi (2014) e art. $15^{\circ}$ IN RFB 1312, de 28 de dezembro de 2012.

\subsubsection{Do Método do Preço Sob Cotação na Importação (PCI)}

Este é definido como os valores médios diários da cotação de bens ou direitos sujeitos a preços públicos em bolsas de mercadorias e futuros internacionalmente reconhecidos (art. 18-A da Lei ${ }^{\circ} 9.430$ de 1996), Higuchi (2014) e art. $16^{\circ}$ IN RFB 1312, de 28 de dezembro de 2012.

\subsubsection{Do Método do Preço de Venda nas Exportações (PVEx)}

O mesmo é definido como sendo a média aritmética dos preços nas exportações efetuadas pela própria empresa, para outros clientes que não sejam vinculados, ou por outra exportadora nacional de bens, serviços ou direitos idênticos ou similares durante um mesmo período de apuração, PriceWaterhouse (1998), Matos (1999) e art. 30 IN RFB 1312, de 28 de dezembro de 2012.

\subsubsection{Do Método do Preço de Venda por Atacado no País de Destino, Diminuído do Lucro (PVA)}

Define que, o PVA como média aritmética dos preços de venda de bens, idênticos ou similares, praticado no mercado atacadista do país de destino, em semelhantes condições de pagamento, diminuídos os tributos incluídos ao preço, cobrados no referido país, e da margem de $15 \%$ de lucro sobre o preço bruto e venda no atacado, PriceWaterhouse (1998), Matos (1999) e art. $31^{\circ}$ IN RFB 1312, de 28 de dezembro de 2012.

\subsubsection{Do Método do Preço de Venda a Varejo no País de Destino, Diminuído do Lucro (PVV)}

Este método é definido como média aritmética dos preços de venda e bens, sendo este idênticos ou similares, eles praticados no mercado varejista do país de destino, diminuídos dos tributos incluídos ao preço, com uma margem de $30 \%$ aplicada sobre o preço bruto de venda no varejo, PriceWaterhouse (1998), Matos (1999) e art. 32 IN RFB 1312, de 28 de dezembro de 2012.

\subsubsection{Do Método do Custo de Aquisição ou de Produção mais Tributos e Lucro (CAP)}

O CAP é conceituado como média aritmética dos custos de aquisição ou da produção de bens, serviços e direitos exportados, acrescido dos impostos e contribuições cobrados no Brasil, e com uma margem de $15 \%$ sobre os custos mais impostos e contribuições, PriceWaterhouse (1998), Matos (1999) e art. $33^{\circ}$ IN RFB 1312, de 28 de dezembro de 2012. 


\subsubsection{Do Método do Preço sob Cotação na Exportação (Pecex)}

O mesmo é definido como sendo os valores médios diários da cotação dos bens ou direitos sujeitos a preços públicos em bolsas de mercadorias e futuros internacionalmente sendo estes reconhecidos (art. 19-A lei $\mathrm{n}^{\circ} 9.430$ de 1996), art. 34 IN RFB 1312, de 28 de dezembro de 2012.

\subsection{Operações Back to Back}

A mesma tem como principal finalidade a redução dos custos relacionados a importação e exportação de mercadorias. Desta maneira a empresa tem um grande ganho logístico, sendo que a mercadoria não "entra e sai" do território brasileiro, e o tempo de entrega ao destinatário final é bem reduzido, Silva (2014) e art. $374^{\circ}$ da IN RFB n ${ }^{\circ} 1.312 / 2012$.

\subsection{A Declaração País-a-País (DPP)}

Foi instituída pela Instrução Normativa RFB no 1.681/2016, de 28 de dezembro de 2016, em cumprimento ao compromisso acordado em âmbito internacional, sigla em inglês para Base Erosionand Profit Shifting (Erosão da Base Tributável e Transferência de Lucros), coordenado conjuntamente pelos países-membros do G-20 e da Organização para a Cooperação e o Desenvolvimento Econômico (OCDE).

Estão obrigados à entrega da Declaração País-a-País os grupos multinacionais cujo a sua receita consolidada total no ano fiscal anterior ao da declaração for igual ou superior a $\mathrm{R} \$ 2.260$ milhões ou o equivalente a 750 milhões de Euros, ou o equivalente a moeda local de sua jurisdição para os fins tributários com data base de sua conversão em 31 de janeiro de 2015. Os demais grupos multinacionais estão dispensados do cumprimento da obrigação conforme o art. $4^{\circ}$ da IN 1.681/2016.

\section{PROCEDIMENTOS METODOLÓGICOS}

O método indica a forma como se pretende investigar uma pesquisa e quais os procedimentos para se conduzir uma pesquisa (CHEMIN, 2015).

O tipo de pesquisa deste artigo é o estudo exploratório, que ser usado quando há poucos ou nenhum estudo anterior, onde existe a possibilidade de buscar informações sobre a questão ou o problema, onde o foco é obter a familiaridade com a área do assunto para uma investigação mais rigorosa em um momento seguinte (COLLIS, 2005; SAMPIERI, 2013; MARCONI; LAKATOS, 2006; BEUREN, 2006).

Também se aproxima do estudo de caso, segundo Beuren (2006) caracteriza-se principalmente pelo estudo concentrado de um único caso. 
Quanto à abordagem do problema a pesquisa qualitativa, pois tratase de interpretação e estudo mais aprofundado de determinadas maneiras da aplicação do preço de transferência (LEOPARDI apud CHEMIN, 2015).

Os dados foram coletados através das informações obtidas da empresa, tratados quanto a sua aplicabilidade em se tratando de empresas vinculadas, testando-os conforme as hipóteses previstas na legislação brasileira. Para o teste de preços comparáveis conforme a legislação internacional foram convertidos em euros com a taxa de 30 de dezembro de 2017.

Este estudo apresenta limitações, pois a empresa não efetua nenhuma venda a outras empresas, sejam elas de mercado interno ou externo. Ademais não verifica alterações a posterior na lei vigente em dezembro de 2017.

\section{APRESENTAÇÃO DOS RESULTADOS}

O presente estudo trata-se de uma empresa brasileira que é subsidiária de uma empresa estrangeira, a mesma vende toda a sua produção para a sua controladora, em função desta operação entre ambas a empresa brasileira necessita respeitar alguns critérios impostos pela Receita Federal do Brasil no quesito relacionado aos preços de transferência (transfer pricing).

Como se tratam de empresas subsidiárias, as mesmas precisam respeitar o tratamento que a Legislação do Imposto de Renda aplica a operações com esta natureza, para não incorrer em práticas ilegais quanto à sua tributação.

Considerando que a empresa brasileira opera exclusivamente com vendas para a controladora, alguns dos métodos não são aplicáveis dada a natureza da operação, também existe um processo complementar de produção no exterior, o que agrega materiais e custos industriais, assim, da forma como o produto é exportado, não é passível de comercialização nesse estágio.

Considerar que, a produção da empresa pesquisada está focada em tecnologia que não está disponível no Brasil, é um processo realizado na Alemanha completando o processo de produção. A comparação com qualquer produto similar esbarra nesse ponto, a tecnologia é uma exclusividade da empresa controladora sediada no exterior.

Na sequencia, estudou-se a característica de cada um dos métodos e a sua aplicabilidade na operação, buscando o método aplicável.

\subsection{Método do Preço de Venda nas Exportações (PVEx)}

O PVEx, caracteriza-se pela média aritmética dos preços de venda das exportações efetuadas pela própria empresa, para outros clientes não vinculados, ou por outra exportadora nacional de bens, serviços ou direitos, idênticos ou similares, durante um mesmo período de apuração da base de cálculo do Imposto de Renda e com condições de pagamento semelhantes. 
Na sua determinação, devem ser considerados, num mesmo período de apuração e para compradores não vinculados, em condições negociais semelhantes:

- Preço médio das próprias operações;

- Preço médio das exportações de outros clientes.

Este método não se aplica para esta empresa, pois a mesma destina $100 \%$ da sua produção para a sua controladora, desta maneira não é possível aplicar este método para a empresa em estudo.

A empresa opera no Brasil desde 2006, nunca vendeu nada no mercado interno, que não existe produto similar nem igual, no mercado brasileiro.

\subsection{Método do Preço de Venda por Atacado no País de Destino, Diminuído do Lucro (PVA)}

O PVA, caracteriza-se pela média aritmética dos preços de venda de bens, estes idênticos ou similares, praticados no mercado atacadista do país de destino, em condições semelhantes, estes diminuídos dos tributos incluídos no preço, cobrados no referido país, e com margem de lucro de $15 \%$ sobre o preço de venda no atacado.

Na sua determinação, devem ser considerados, num mesmo período de apuração e para compradores não vinculados, em condições negociais semelhantes:

- Média aritmética dos preços de venda, no mercado atacadista do país de destino, de bens e serviços idênticos ou similares, a pessoas não vinculadas;

- (-) Tributos incluídos no preço, cobrados no país de origem, estes semelhantes a ICMS, ISS, PIS e Cofins;

- (-) Margem de lucro de 15\% sobre o preço bruto de venda no atacado.

Como já mencionado no método anterior, a empresa destina $100 \%$ da sua produção para a sua controladora, diante disso este método não se aplica para a empresa em estudo.

Vejamos, o produto no seu destino é comercializado diretamente para o consumo final, ou seja, vendido para empresas que o utilizam como equipamento de segurança.

A empresa controladora, na Alemanha, ao receber o produto agrega componentes e processos de produção de tal forma que o produto não é comercializável no estágio que sai da empresa exportadora brasileira. 


\subsection{Método do Preço de Venda a Varejo no País de Destino, Diminuído do Lucro (PVV)}

O PVV caracteriza-se nas informações do PVA, pois ambos possuem semelhanças em relação as vendas praticadas no varejo, sendo que as mesmas apresentam as diferenças:

- nas vendas a varejo, a margem é de 30\%, diferentemente dos $15 \%$ aplicados no atacado;

- a base de cálculo da margem de lucro, no caso de vendas no atacado, é o preço diminuído dos tributos sobre a venda, enquanto que no varejo é simplesmente o preço, sem qualquer redução.

Como já mencionado no método anterior, a empresa destina $100 \%$ da sua produção para a sua controladora, diante disso este método não se aplica para a empresa em estudo.

O produto não é comercializado a varejo no destino, o produto sofre alterações com agregação de materiais e processos sendo vendido diretamente para empresas, com programação prévia, para atender as exigências das normas de segurança do trabalho. O produto não tem similar no varejo que permita compará-lo.

\subsection{Método do Custo de Aquisição ou de Produção mais Tributos e Lucro (CAP)}

O CAP é definido pela média aritmética dos custos de aquisição ou de produção dos bens, serviços ou direitos, exportados, acrescidos dos impostos e contribuições cobrados no Brasil com uma margem de 15\% sobre a soma dos custos mais impostos e contribuições.

Para a utilização deste método devem ser respeitados os seguintes critérios conforme apresentados:

- Média aritmética dos Custos de Aquisição ou de Produção;

- (+) Fretes e seguros pagos pelo adquirente;

- (-) Crédito Presumido de IPI;

- (+) Impostos e Contribuições Cobrados no Brasil;

- (+) Margem de Lucro de 15\% sobre a soma dos custos mais impostos e contribuições.

Conforme o Regulamento do Imposto de Renda, o mesmo define quais os custos que possuem incidência para a aplicação deste método.

Custo de aquisição: Conforme o artigo 289 do Regulamento do Imposto de Renda, o custo de aquisição de mercadorias destinadas à revenda incluirá os de transporte e seguro até o estabelecimento do contribuinte e os tributos não recuperáveis devidos na aquisição ou importação. 
Custo de produção: Conforme o artigo 290 do Regulamento do Imposto de renda, o custo da produção dos bens ou serviços compreenderá, obrigatoriamente:

a) $\mathrm{O}$ custo de aquisição de matérias-primas e quaisquer outros bens e serviços aplicados ou consumidos na produção, inclusive os de transporte e seguro até o estabelecimento do contribuinte e os tributos não recuperáveis devidos na aquisição da importação;

b) $\mathrm{O}$ custo do pessoal aplicado na produção, inclusive na supervisão direta, manutenção e guarda das instalações de produção;

c) Os custos de locação, manutenção e reparo e os encargos de depreciação dos bens aplicados na produção; produção;

d) Os encargos de amortização, diretamente relacionados com a

e) Os encargos de exaustão dos recursos naturais utilizados na produção.

Para o presente estudo, o CAP é o único método em que a empresa se enquadra, pois, o mesmo atende a legislação brasileira quanto a sua forma de cálculo, o mesmo é formado pelo custo de produção do produto acrescido com uma margem de $15 \%$ sobre os custos de produção.

A empresa atende todos os requisitos do Método (CAP) pois, a mesma possui um controle do custo de produção de todos os seus produtos e estes acrescidos com uma margem de $15 \%$ sobre estes custos, sendo que a soma dos dois serve de preço parâmetro para fins de cálculo do preço de transferência.

Conforme a legislação brasileira o cálculo precisa ser realizado a cada produto, não sendo possível apresentar o mesmo quanto a famílias de produtos.

Conforme o artigo 51 na IN n 1.312 de 28 de dezembro de 2012, é considerado satisfatório a comprovação, nas operações com pessoas jurídicas vinculadas, quando o preço ajustado, este utilizado como parâmetro, pode ser divergente em até $5 \%$ para mais ou para menos, em relação dos preços constantes nos documentos de exportação. Nesta hipótese não será necessário nenhum ajuste na apuração do imposto de renda e na base de cálculo da CSLL.

No Quadro 3 é demonstrado o cálculo pelo método CAP referente aos custos de produção acrescidos da margem de $15 \%$, sendo este o preço parâmetro e apresentado o preço de venda de cada modelo conforme a legislação ora vigente. 
Quadro 3 - Cálculo do método CAP

\begin{tabular}{|l|c|c|c|c|}
\hline Modelo & Custo de Produção & $\begin{array}{c}\text { Preço Parâmetro R\$ Custo } \\
+15 \% \text { Lucro } \\
(\mathrm{b}=\mathrm{a} \times 1,15)\end{array}$ & Preço Venda R\$ (c) & Margem \% \\
$(\mathrm{d}=\mathrm{c} \div \mathrm{b})$
\end{tabular}

Fonte: elaborado pelo Autor com base nas informações da empresa do ano de 2017.

Conforme dados obtidos com base nas informações da empresa e através de publicação em revista industrial da Europa, segue um comparativo de preços em relação à produção de calçados na Europa, e o valor de venda dos calçados do mesmo segmento produzidos no Brasil e revendidos para a Europa. A conversão de $\mathrm{R} \$$ para $\mathrm{E} \$$ utilizou a taxa média de dezembro do ano de 2017 fornecida pelo Banco Central do Brasil

Quadro 4 - Comparativo entre custo de produção e custo de importação

\begin{tabular}{|c|c|}
\hline $\begin{array}{c}\text { Custo de Produção na } \\
\text { Europa - Preço Unitário } €\end{array}$ & $\begin{array}{c}\text { Custo de Importação do } \\
\text { Brasil - Preço Unitário } €\end{array}$ \\
\hline 26,73 & 20,00 \\
\hline
\end{tabular}

Fonte: elaborado pelo Autor com base nas informações da empresa. 
Os dados do Quadro 4 foram obtidos através de informações da empresa, estes foram apurados através da aplicação da média simples dos preços hora praticados e apresentados.

Pelos dados aqui apresentados, e pelo estudo em relação ao preço de transferência, verifica-se que estes produtos produzidos aqui no Brasil, ainda se tornam mais baratos considerando todos os custos de importação e de transporte até o seu destino final.

Sendo assim, a empresa Brasileira atende plenamente a legislação vigente em dezembro de 2017, com relação ao Método em que a mesma se enquadra. Em relação ao preço internacional não é possível afirmar o atendimento da legislação pois não foram disponibilizadas informações da controladora para verificação.

Foram realizadas tentativas na comparação de preços junto com outros fabricantes brasileiros do mesmo segmento, mas isto não foi possível devido a empresas que produziam e revendiam seus produtos para o mesmo país não estarem mais operando com o mercado estrangeiro.

Uma empresa está localizada em São Paulo, a mesma não comercializa mais para o mercado externo, atualmente atua somente no mercado interno, inclusive a mesma encerrou as suas atividades não sendo mais possível obter informações da mesma.

A única empresa do Rio Grande do Sul que operava no segmento localizada em Novo Hamburgo e encerrou as suas atividades não sendo possível obter informações da mesma, assim como, o produto não tinha similaridade com o produzido pela empresa pesquisada.

\section{CONSIDERAÇÕES FINAIS}

O presente trabalho propôs-se a identificar se a empresa em estudo vem atendendo a Lei $\mathrm{n}^{\circ}$ 9.430/96, preços de transferência entre vinculadas (transfer pricing). Foram citados e analisados os métodos possíveis de serem utilizados entre empresas vinculadas.

Dentre os métodos verificados a empresa não efetua nenhuma venda a terceiros, seja no mercado interno e externo, desta maneira a mesma não pode utilizar os métodos do PVEx, PVV e PVA, pois não existem meios de equiparação de preços, visto que a totalidade de sua produção é vendida para empresa vinculada e desta forma vem atendendo criteriosamente a Lei.

O único método possível em que a empresa se enquadra é o método pelo CAP, o mesmo é composto pelo custo de produção acrescido de margem de $15 \%$ sobre os custos de produção, desta maneira a mesma atende a Lei ora vigente em dezembro de 2017.

Dessa forma, perante a legislação brasileira e conforme argumentado a empresa não pratica atos de evasão e sonegação fiscal, pois a mesma demonstra 
através do cálculo que não posterga o pagamento de impostos por práticas de atos ilícitos.

Para estudos futuros sugere-se uma verificação do atendimento da legislação européia, quanto a sua aplicabilidade e se a mesma está sendo atendida conforme a legislação em vigor.

\section{REFERÊNCIAS}

AMARAL, Gilberto Luiz do. Planejamento Tributário e a Norma Geral Antielisão. 1. ed. Curitiba: Juruá, 2003.

BEUREN, Ilse Maria. Como Elaborar Trabalhos Monográficos em Contabilidade. 3. ed. São Paulo: Atlas, 2006.

BRASIL. Instrução Normativa RFB No $\mathbf{1 3 1 2}$, de 28 de dezembro de 2012. Preços de Transferência. Disponível em: <http:/ / www.receita.fazenda.gov.br>. Acesso em: 26 jun. 2017.

. Instrução Normativa RFB No 1681, de 28 de dezembro de 2016. Declaração País-a-País. Disponível em: <http:/ /www.receita.fazenda.gov.br>. Acesso em: 26 jun. 2017.

. Ministério da Fazenda. Organização de Cooperação e Desenvolvimento Econômico (OCDE). Disponível em: <http:/ / www.sain.fazenda.gov.br/assuntos/ politicas-institucionais-economico-financeiras-e-cooperacao-internacional/OCDE> . Acesso em: 11 nov. 2017

CHEMIN, Beatriz Francisca. Manual da Univates para trabalhos acadêmicos: planejamento, elaboração e apresentação. 3. ed. Lajeado: Univates, 2015. E-book. Disponível em: <www.univates.br>. Acesso em: 09 jun. 2017.

COLLIS, Jill, Hussey Roger. Pesquisa em administração. 2. ed. Porto Alegre: Bookman, 2005.

FILHO, Edmar Oliveira Andrade. Planejamento Tributário. São Paulo: Saraiva 2009.

HIGUCHI, Hiromi. Imposto de Renda das Empresas. 39. ed. São Paulo, 2014.

HORNGREN, CharlesT.; FOSTER, George; DATAR, Srikant M. Contabilidade de Custos. 9. ed. Rio de Janeiro: LTC, 2000.

INTERNATIONAL ACCOUNTING STANDARDS COMMITTE. Normas Internacionais de Contabilidade: NIC 24. São Paulo; IBRACON, 1998.

MARCONI, M. de A.; LAKATOS, E. M. Técnicas de pesquisa. 6. ed. São Paulo: Atlas, 2006.

MARTINS, Sérgio Pinto. Manual de Direito Tributário. 5. ed. São Paulo: Atlas 2006. 
MATOS, Fernando. Preços de Transferência no Brasil. São Paulo: Atlas 1999.

OLIVEIRA, Gustavo Pedro de. Contabilidade Tributária. 4. ed. São Paulo: Saraiva, 2013.

ROSSETTO, Vicente. Tendências da sistemática brasileira de transferpricing. 1999

SÁ, Antônio Lopes de; HOOG, Wilson Alberto Zappa. Corrupção, Fraude e

Contabilidade. Curitiba: Juruá, 2007.

SILVA, Lourivaldo Lopes da. Manual do Preço de Transferência. São Paulo: IOB SAGE, 2014.

TÔRRES, Heleno. Direito Tributário e Direito Privado: autonomia privada, simulação, elusão tributária. São Paulo: Revista dos tribunais, 2003.

WATERHOUSE, Price. Preço de Transferência. São Paulo: Atlas, 1998.

WORLD INTEGRATED TRADE SOLUTION - WITS. Disponível em: <https:/ / wits. worldbank.org/CountryProfile/en/Country/DEU/Year/2016/TradeFlow/Import / Partner/All/Product/64-67_Footwear>. Acesso em: 15 jan. 2018. 